\title{
Demographic and Clinical Features Associated with in-Hospital Mortality in Egyptian COVID-19 Patients: A Retrospective Cohort Study
}

Noha Asem $^{1}$, Mohamed Hassany ${ }^{2}$ D, Khaled Taema $^{3 *}$ (D), Hossam Masoud ${ }^{4}$ (D) , Gehan Elassal ${ }^{5}$, Ehab Kamal ${ }^{6,7}$, (D), Wagdy Abdel Moneim Amin ${ }^{6}$, Akram Abdelbary ${ }^{3}$ D, Amin Mohamed Abdel Baki ${ }^{9}$, Samy Zaky ${ }^{10}$, Ahmad Said Abdalmohsen ${ }^{3}$, Hamdy Mohamed Ibrahim $^{11}$, Mohamed Abdel Hakim Elnady ${ }^{4}$, Ahmed Sh. Mohamed ${ }^{12}$, Ehab Attia ${ }^{13}$, Hala Zaid ${ }^{13}$

${ }^{1}$ Department of Public Health and Community Medicine, Faculty of Medicine, Cairo University, Ministry of Health and Population, Cairo, Egypt; ${ }^{2}$ Department of Hepatology and Tropical Medicine, National Hepatology and Tropical Medicine Research Institute, Ministry of Health and Population, Cairo, Egypt; ${ }^{3}$ Department of Critical Care Medicine, Faculty of Medicine, Cairo University, Cairo, Egypt; ${ }^{4}$ Department of Pulmonology, Cairo University, Cairo, Egypt; ${ }^{5}$ Department of Pulmonology, Ain Shams University, Cairo, Egypt; ${ }^{6}$ Department of Research and Training, Medical Research Division, National Research Centre, Giza, Egypt; ${ }^{7}$ Minster of Health Assistant for Continuous Medical Education, Head of Fever Hospitals Directorate, Ministry of Health and Population, Cairo, Egypt; ${ }^{8}$ Department of Chest Diseases, Ministry of Health and Population, Cairo, Egypt; ${ }^{9}$ Department of Hepatology, Gastroenterology and Infectious Diseases, National Hepatology and Tropical Medicine Research Institute, Cairo, Egypt; ${ }^{10}$ Department of Hepatogastroenterology and Infectious Diseases, Alazhar University, Cairo, Egypt; ${ }^{11}$ Intensive Care Unit, National Hepatology and Tropical Medicine Research Institute, Cairo, Egypt; ${ }^{12}$ Department of Chest Diseases and Bronchscopy, Tanta University, Tanta, Egypt; ${ }^{13}$ Minster of Health and Population, Ministry of Health and Population, Cairo, Egypt Citation: Asem N, Hassany M, Taema K, Masoud H, ssal G, Kamal E, Amin WAM, Abdelbary A, Baki AMA, Zaky S, Abdalmohsen AS, Ibrahim HM, Elnady MAH Mohamed AS, Attia E, Zaid H. Demographic and Clinical eatures Associated with in-Hospital Mortality in Egyptian COVID-19 Patients. A Retrospective Cohort Study. penAccessMaced JMedSci. 2021 Nov10;9(E):1068-1075 https://doi.org/10.3889/oamjms.2021.722 Keywords: COVID-19; SARS-COV-2; In-hospital mortality "Correspondence: Khaled Taema, Department of E-mail: khaled toaima@kasralainy edueg Received: 05-Sep-202 Received: 05-Sep-2021 Accepted: 09-Nov-202 Copyright: () 2021 Noha Asem, Mohamed Hassany, Kaled Taema, Hossam Masoud, Gehan Elassal, Ehab Kamal, Wagdy Abdel Moneim Amin, Akram Abdelbary, Amin Mohamed Abdel Baki, Samy Zaky, Ahmad Said Abdakn ha Mo Mr

Abdel Hakim Elnady, Ahmed Sh. Mohamed, Ehab Attia,

Funding: This research received funding from the Egyptian Ministry of Health and Competing Interests: The authors have declared that no

competing interests exist under the terms of the Creative Commons Attribution-

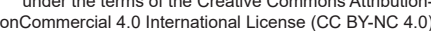

\section{Abstract}

AIM: We evaluated in this study the demographic and clinical characteristics of COVID-19 disease in the Egyptian population with special consideration for its mortality predictors.

METHODS: About 8162 participants (mean age $48.7 \pm 17.3$ years, $54.5 \%$ males) with RT-PCR positive COVID-19 were included. The electronic medical records were reviewed for demographic, clinical, laboratory, and radiologic features. The primary outcome was the in-hospital mortality rate.

RESULTS: The in-hospital mortality was $11.2 \%$. There was a statistically significant strong association of in-hospital mortality with age $>60$-years-old (OR: $4.7 ; 95 \% \mathrm{Cl} 4.1-5.4 ; \mathrm{p}<0.001$ ), diabetes mellitus (OR: 4.6 ; $95 \% \mathrm{Cl} 3.99-5.32$ $p<0.001$ ), hypertension (OR: $3.9 ; 95 \% \mathrm{Cl} 3.4-4.5 ; \mathrm{p}<0.001)$, coronary artery disease (OR: $2.7 ; 95 \% \mathrm{Cl} 2.2-3.2$; $\mathrm{p}<0.001$ ), chronic obstructive pulmonary disease (OR: $2.1 ; 95 \% \mathrm{Cl} 1.7-2.5 ; \mathrm{p}<0.001$ ), chronic kidney disease (OR: 4.8; 95\% Cl 3.9-5.9; $p<0.001$ ), malignancy (OR: 3.7; 95\% Cl 2.3-5.75; $p<0.001$ ), neutrophil-lymphocyte ratio $>3.1$ (OR: $6.4 ; 95 \% \mathrm{Cl} 4.4-9.5 ; \mathrm{p}<0.001$ ), and ground glass opacities (GGOs) in CT chest (OR: $3.5 ; 95 \%$ $\mathrm{Cl} 2.84-4.4 ; \mathrm{p}<0.001)$, respectively. There was a statistically significant moderate association of in-hospital mortality with male gender (OR: 1.6; 95\% Cl 1.38-1.83; $\mathrm{p}<0.001$ ) and smoking (OR: 1.6; 95\% Cl 1.3-1.9; $\mathrm{p}<0.001$ ). GGOs was reported as the most common CT finding (occurred in $73.1 \%$ of the study participants).

CONCLUSION: This multicenter, retrospective study ascertained the higher in-hospital mortality rate in Egyptian COVID-19 patients with different comorbidities.

\section{Introduction}

A pneumonia outbreak caused by a novel coronavirus, the severe acute respiratory syndrome coronavirus-2 (SARS-CoV-2), has been identified at the end of 2019 in Wuhan city, China. The pneumonia outbreak spread rapidly crossing international boundaries and was declared as a global pandemic by the WHO on March 11, 2020 [1], [2]. The disease is designated COVID-19, which stands for coronavirus disease 2019 [3].
Acute COVID-19 pneumonia induced acute respiratory distress syndrome (ARDS) is a potential significant concern for morbidity and mortality, besides other induced life-threatening complications that include, but are not limited to, arrhythmias, acute cardiac injury, and shock. Critical illness mainly occurs in elderly individuals, especially with underlying comorbidities as diabetes mellitus (DM), hypertension, coronary artery disease (CAD), malignancy, chronic obstructive pulmonary disease (COPD), and/or chronic kidney disease (CKD) [4]. Laboratory parameters associated 
with severe disease and related to disease progression include ferritin and D-Dimer [5].

On February 15, 2020, Egypt declared the first reported COVID-19 patient [6] which increased to a range of 710-5241 patients by March $31^{\text {st }}$ [7]. In February 2020 , the Egyptian Ministry of Health designated a scientific committee for steering the national clinical COVID-19 management protocol. Due to the lack of evidence for the effectiveness of any antiviral therapy in the management of COVID-19, resource allocation to repurpose the utilization of antiviral and non-antiviral medications approved for the treatment of other diseases was a potential mitigation measure for the current pandemic [8]. It is reported that both chloroquine and hydroxychloroquine (potent inhibitors of DNA and RNA polymerase reactions) inhibit SARS-CoV-2 in vitro [9], [10]. These medications are authorized as antimalarials and used in the management of autoimmune disorders, including systemic lupus erythematosus and rheumatoid arthritis. Considering its' in vitro activity [9], [10], safety for inpatient use [11], availability, and effectiveness in some pilot non-randomized studies [12], [13], [14], the scientific committee advocated the use of hydroxychloroquine as the main antiviral therapy in the Egyptian COVID-19 management protocol.

We intended to investigate the demographic, clinical, laboratory, and radiologic features associated with in-hospital mortality in the Egyptian COVID-19 patient population.

\section{Methods}

\section{Study design}

This was an observational, multicenter, retrospective cohort study conducted at 17 COVID-19 quarantine hospitals in Egypt from March $20^{\text {th }}$ till May $30^{\text {th }}$, 2020. The study design was approved by the research ethics committee and the institutional review board of the Egyptian Ministry of Health and Population. The informed consent for data collection was obtained from patients or first degree relatives, the study procedures were carried out following the Code of Ethics of the World Medical Association (Declaration of Helsinki), all information/images were anonymized and coded, and the privacy and confidentiality rights of the study participants were observed throughout the study.

\section{Study participants}

Study participants were patients with symptoms suggestive of COVID-19 referred for admission. They were subjected to history taking and data collection for age, gender, smoking, pregnancy, comorbidities especially COPD, rheumatic heart disease, DM, hypertension, CAD, chronic liver disease, CKD, autoimmune disease and malignancy, and nasopharyngeal or oropharyngeal swab for reverse transcription-polymerase chain reaction (RT-PCR) of SARS-CoV-2. Screened participants were enrolled if they were admitted with COVID-19 disease, confirmed by RT-PCR positive nasopharyngeal or oropharyngeal swab, and excluded if they were RT-PCR negative COVID-19 disease.

\section{Study procedures}

A clinical COVID-19 management protocol was prepared by the Egyptian Ministry of Health COVID-19 scientific steering committee. An educational task force was established to update the healthcare providers on the COVID-19 management protocol. Several hospitals were designated for quarantine of patients with COVID-19. All study participants were followed retrospectively from the admission date to the discharge date. Nasopharyngeal or oropharyngeal swab for RT-PCR of SARS-CoV-2 was repeated every $72 \mathrm{~h}$ after clinical remission of COVID-19 symptoms. The discharge criteria were the absence of the COVID-19 symptoms for at least 3 days, improvement in the radiologic findings, and two consecutive negative nasopharyngeal or oropharyngeal swabs for RT-PCR of SARS-CoV-2 obtained at least $48 \mathrm{~h}$ apart. Epidemiological, demographic, clinical, laboratory, radiologic, treatment, and outcome data were extracted from the study participants' standardized electronic medical records designated for COVID-19 quarantine hospitals.

\section{End points}

The primary outcome was the in-hospital mortality rate while the secondary outcome was the negative RT-PCR conversion rate and the time to negative RT-PCR conversion.

\section{Statistical analysis}

Retrospective data from the study participants' standardized electronic medical records were collected and coded, and the data were analyzed using the statistical package for the social sciences software version 25. A quantitative (continuous) variable was considered parametrically (normally) distributed if the z-value of skewness and kurtosis was between -1.96 and +1.96 [15] and the Shapiro-Wilk's test had a p > 0.05 [16]. We found that our quantitative (continuous) variables were parametrically (normally) distributed. Accordingly, quantitative (continuous) data were expressed as means and standard deviations. Parametrically distributed quantitative (continuous) variables were compared with the Independent two-tailed t-test. Qualitative (categorical) data were expressed as proportions. Qualitative (categorical) variables were compared with Chi-square 
test $\left(\chi^{2}\right)$. The probability of in-hospital mortality was expressed as odds ratio (OR). The confidence interval was set to $95 \%(95 \% \mathrm{Cl})$ and the margin of error accepted was set to $5 \%$. Any comparison considered statistically significant was at $p \leq 0.05$.

\section{Results}

\section{Study participants and procedures}

We reviewed the standardized electronic medical records of 8162 patients with RT-PCR positive COVID-19 disease from 17 hospitals in one country from March $20^{\text {th }}$ till May $30^{\text {th }}, 2020$. The study group was disproportionate with regards to the demographic data, comorbidities, disease severity, and baseline laboratory findings (Table 1). The key sociodemographic feature of the enrolled participants was slight male predominance (Mean age $48.7 \pm 17.3$ years, $54.5 \%$ males, $45.5 \%$ females). All enrolled participants completed the study and there were no withdrawals.

The main presenting clinical features of the study participants were fever (69.8\%; 95\% Cl 68.8-70.8\%) and cough (67.5\%; $95 \% \mathrm{Cl} 66.5-68.5 \%$ ), respectively (Figure 1). The most common CT finding was the ground glass opacities (GGOs) which were reported in 5962 study participants $(73.1 \%$; 95\% Cl $72.1-74 \%)$. There was septal thickening in 2384 study participants $(29.2 \%$; $95 \% \mathrm{Cl} 28.2-30.2 \%$ ), consolidation in 2884 study participants (35.3\%; 34.3-36.4\%), Iymphadenopathy in 1470 study participants (18\%; 95\% Cl 17.2-18.8\%), pleural effusion in 653 study participants $(8 \%$; 95\% Cl 7.4-8.6\%), peripheral subpleural involvement in 4163 study participants (51\%; 95\% Cl 49.9-52.1\%), and multilobar involvement in 4679 study participants (57.3\%; 95\% Cl 56.3-58.4\%), respectively. Pneumonia was the most common complication in our cohort, reported in 1425 study participants (17.5\%; 95\% Cl 16.6-18.3\%). There was ARDS in 996 study participants $(12.2 \%$; $95 \% \mathrm{Cl} 11.5-12.9 \%)$, cardiac arrhythmias in 112 study participants (1.4\%; 95\% Cl $1.1 \%-1.6 \%)$, myocarditis in 191 study participants (2.3\%; 95\% Cl 2-2.7\%), disseminated intravascular coagulopathy in 320 study participants (3.9\%; 95\% Cl $3.5-4.3 \%)$, bleeding events in 12 study participants $(0.15 \% ; 95 \% \mathrm{Cl} 0.06-0.23 \%)$, acute kidney injury in 350 study participants (4.29\%; 95\% Cl 3.9-4.7\%), acute liver injury in 204 study participants $(2.5 \%$; 95\% Cl 2.2-2.8\%), and septic shock in 1098 study participants (13.5\%; 95\% Cl 12.7-14.2\%), respectively.

\section{Clinical, laboratory, and radiologic features associated with in-hospital mortality}

A total of 7247 study participants survived their hospital course, while 915 study participants died with an in-hospital mortality rate of $11.2 \%$ (95\% Cl 10.5-11.9\%). The highest mortality rate was in the severe/critical subgroup (646 study participants) (46.7\%; 95\% Cl 44.0-49.3\%) compared to the mild subgroup (68 study participants) $(1.6 \% ; 95 \% \mathrm{Cl} 1.2-2.0 \%)$ and the moderate subgroup (201 study participants) $(7.7 \%$; $95 \%$ Cl 6.7-8.7\%), respectively $(p<0.001)$. The in-hospital mortality was $23.5 \%$ in patients $>60$-years-old compared to $6.1 \%$ in those $<65$-years-old ( $p<0.001$ ). The in-hospital mortality was reported in $8.3 \%$ of patients with no comorbidities (511/6182) compared to $16.3 \%$ (159/977), 21\% (145/690), and 31.9\% (100/313) of patients with one, two, and three or more comorbid conditions, respectively ( $p<0.001$ ) (Figure 2 ).

There was a statistically significant strong association of in-hospital mortality with age $>60$-years-old (OR: 4.7; 95\% Cl 4.1-5.4), DM (OR: 4.6; 95\% Cl 3.99 5.32), hypertension (OR: 3.9; 95\% Cl 3.4-4.5), CAD (OR: 2.7; 95\% Cl 2.2-3.2), COPD (OR: 2.1; 95\% Cl 1.7-2.5), chronic liver disease (OR: 2.5; 95\% Cl 2.04-3.2), CKD (OR: 4.8; 95\% Cl 3.9-5.9), and malignancy (OR: $3.7 ; 95 \% \mathrm{Cl} 2.3-5.75$ ), respectively

Table 1: The demographic data, comorbidities, disease severity, and baseline laboratory findings of the study population

\begin{tabular}{|c|c|c|c|c|}
\hline Variable & $\begin{array}{l}\text { Number } \\
(8162)\end{array}$ & $\%(95 \% \mathrm{Cl})$ & Variable & Mean \pm SD $(95 \% \mathrm{Cl})$ \\
\hline Male gender & 4448 & $54.5 \%(53.4-55.6 \%)$ & Hemoglobin (gm/dL) & $12.3 \pm 2.4(12.2-12.4)$ \\
\hline Age $>60$-years-old & 2391 & $29.3 \%(28.3-30.3 \%)$ & $\operatorname{TLC}\left(\times 10^{3} / \mathrm{ccm}\right)$ & $7.8 \pm 4.8(7.6-7.95)$ \\
\hline Chronic chest disease & 898 & $11 \%(10.3-11.7 \%)$ & Neutrophils (x103/ccm) & $6.8 \pm 7.2(6.4-7.17)$ \\
\hline Rheumatic heart disease & 152 & $1.86 \%(1.57-2.16 \%)$ & Lymphocytes $\left(\mathrm{x} 10^{3} / \mathrm{ccm}\right)$ & $2.5 \pm 1.8(2.43-2.57)$ \\
\hline Diabetes mellitus & 2522 & $30.9 \%(29.9-31.9 \%)$ & Platelets $\left(\times 10^{3} / \mathrm{ccm}\right)$ & $254 \pm 117(249-258)$ \\
\hline Hypertension & 2726 & $33.4 \%(32.4-34.4 \%)$ & $\operatorname{ESR}(\mathrm{mm} / \mathrm{hr})$ & $40 \pm 31(34-45)$ \\
\hline Coronary heart disease & 743 & $9.1 \%(8.5-9.7 \%)$ & $\operatorname{CRP}(\mathrm{mg} / \mathrm{L})$ & $47.2 \pm 58.7(43.6-50.8)$ \\
\hline Chronic liver disease & 522 & $6.4 \%(5.9-6.9 \%)$ & ALT (IU/L) & $40 \pm 87(36-43)$ \\
\hline Chronic kidney disease & 416 & $5.1 \%(4.6-5.6 \%)$ & AST (IU/L) & $41 \pm 61(39-43)$ \\
\hline Pregnancy & 64 & $0.8 \%(0.6-0.98 \%)$ & Total Bilirubin (mg/dL) & $3 \pm 8.3(1.2-4.8)$ \\
\hline Auto-immune disease & 204 & $2.5 \%(2.2-2.8 \%)$ & INR & $1.6 \pm 6.3(1.2-1.9)$ \\
\hline Malignancy & 90 & $1.1 \%(0.9-1.3 \%)$ & Serum creatinine $(\mathrm{mg} / \mathrm{dL})$ & $1.3 \pm 2.1(1.3-1.4)$ \\
\hline Smokers & 1355 & $16.6 \%(15.8-17.4 \%)$ & Serum albumin $(\mathrm{g} / \mathrm{dL})$ & $3.8 \pm 2.2(3.6-4.0)$ \\
\hline Organ transplant & 57 & $0.7 \%(0.5-0.9 \%)$ & $\mathrm{D}$-dimer $(\mathrm{micg} / \mathrm{mL})$ & $2.8 \pm 7.1(1.8-3.8)$ \\
\hline \multicolumn{5}{|l|}{ Baseline severity } \\
\hline Mild & 4173 & $51.1 \%(50.0-52.2 \%)$ & Troponin (ng/mL) & $0.3 \pm 0.3(0.1-0.4)$ \\
\hline Moderate & 2605 & $31.9 \%(30.9-32.9 \%)$ & Serum Ferritin (ng/mL) & $523 \pm 474(451-595)$ \\
\hline \multirow[t]{2}{*}{ Severe/Critical } & 1384 & $17 \%(16.1-17.8 \%)$ & RBS (mg/dL) & $172 \pm 109(162-183)$ \\
\hline & & & CPK (U/L) & $52 \pm 40(43-61)$ \\
\hline
\end{tabular}


$(p<0.001)$. There was a statistically significant moderate association of in-hospital mortality with male gender (OR: 1.6; 95\% Cl 1.38-1.83) and smoking (OR: $1.6 ; 95 \% \mathrm{Cl} 1.3-1.9)$, respectively $(p<0.001)$ (Table 2).

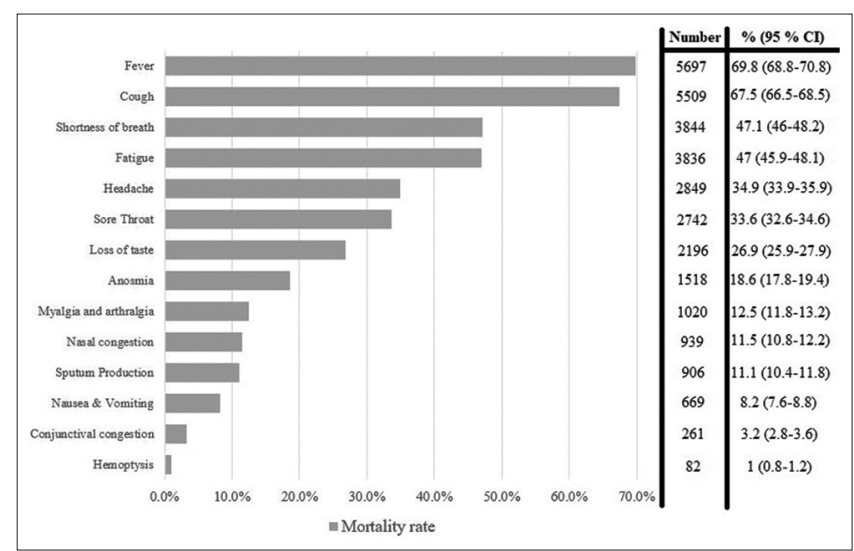

Figure 1: The clinical presentation of the study population

Apart from the occurrence of bleeding, the presence of any of the complications, or the presence of any of the CT findings was associated with a significantly higher risk for mortality (Figures 3 and 4).

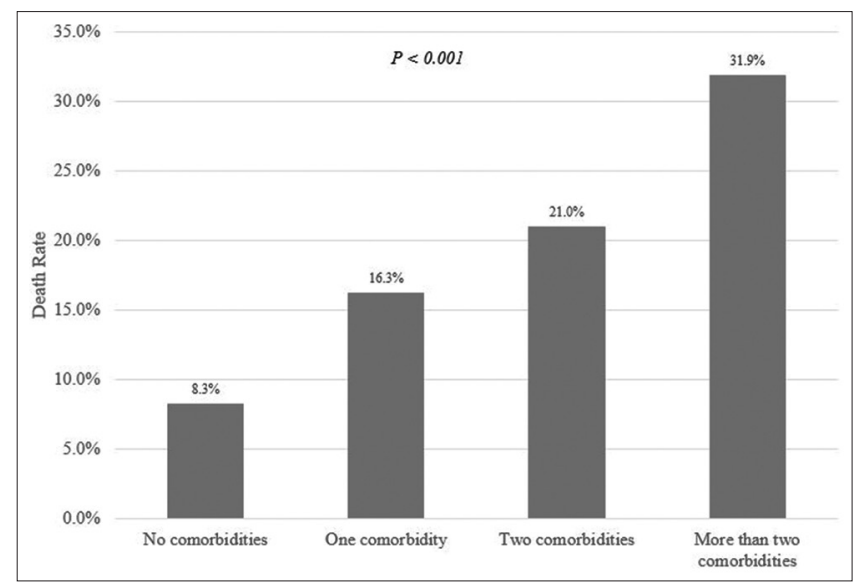

Figure 2: The mortality rate with the different categories of comorbid conditions

The lower serum hemoglobin level, higher total leucocytic count, lower lymphocytic count, higher alanine transaminase (ALT) and aspartate transaminase (AST), higher C-reactive protein (CRP), higher serum creatinine and ferritin levels, lower serum albumin, and higher admission random blood sugar were shown to be significantly associated with higher in-hospital mortality (Table 3).

Neutrophil lymphocyte ratio (NLR) was available in 1398 study participants in the moderate and severe/critical subgroups only. A total of 192 study participants with NLR >3.1 died (26\%) compared to 34 study participants with NLR $<3.1(5.2 \%)$. There was a statistically significant strong association of in-hospital mortality with NLR >3.1 (OR: 6.4; 95\% Cl 4.4-9.5) and GGOs in CT chest (OR: 3.5; 95\% Cl 2.84-4.4), respectively $(p<0.001)$.

\section{Negative RT-PCR conversion rate and time to negative RT-PCR conversion}

The negative RT-PCR conversion rate was $86.2 \%$ by the $12^{\text {th }}$ day of treatment and $95.9 \%$ after the $18^{\text {th }}$ day of treatment with a peak of $15.2 \%$ on the $3^{\text {rd }}$ day of treatment (Figure 5).

\section{Discussion}

With the emergence of the first COVID-19 patient in Egypt on 15/02/2020 [6], the Egyptian Ministry of Health and Population designated a scientific committee for steering a national COVID-19 management protocol to admit and treat COVID-19 patients in quarantine hospitals. In this study, we analyzed data of 8162 patients with RT-PCR positive COVID-19 disease admitted in 17 Egyptian quarantine hospitals from March $20^{\text {th }}$ till May $30^{\text {th }}, 2020$.

Fever and dry cough were the most common presentations of COVID-19 patients [17], [18], [19]. Fever and cough were reported in $69.8 \%$ and $67.5 \%$ of our study participants. In another study [17], fever was reported in $94 \%$ of patients and cough in $79 \%$ of patients. These symptoms of presentation were not, however, associated with mortality [17].

Our study's overall in-hospital mortality was $11.2 \%$. According to the baseline severity of illness identified on presentation to the healthcare facilities, the mortality rates were $1.6 \%, 7.7 \%$, and $46.7 \%$ for mild, moderate, and severe/critical cases, respectively.

Table 2: Clinical predictors of mortality

\begin{tabular}{|c|c|c|c|c|c|}
\hline Variable & Number of patients & Number of deaths & Mortality rate $(95 \% \mathrm{Cl})$ & OR $(95 \% \mathrm{Cl})$ & $p$ value \\
\hline Male gender & 4448 & 589 & $13.2 \%(12.3-14.2 \%)$ & $1.6(1.38-1.83)$ & $<0.001$ \\
\hline 60 or more years old & 2391 & 561 & $23.5 \%(21.8-25.2 \%)$ & $4.7(4.1-5.4)$ & $<0.001$ \\
\hline Pregnancy & 64 & 3 & $4.7 \%(-0.5-9.9 \%)$ & $0.39(0.12-1.24)$ & 0.061 \\
\hline Chronic obstructive pulmonary disease & 898 & 171 & $19.0 \%(16.5-21.6 \%)$ & $2.1(1.7-2.5)$ & $<0.001$ \\
\hline Diabetes mellitus & 2522 & 575 & $22.8 \%(21.2-24.4 \%)$ & $4.6(3.99-5.3)$ & $<0.001$ \\
\hline Hypertension & 2726 & 569 & $20.9 \%(19.3-22.4 \%)$ & $3.9(3.4-4.5)$ & $<0.001$ \\
\hline Coronary heart disease & 743 & 170 & $22.9 \%(19.9-25.9 \%)$ & $2.7(2.2-3.2)$ & $<0.001$ \\
\hline Chronic liver disease & 522 & 119 & $22.8 \%(19.2-26.4 \%)$ & $2.5(2.04-3.2)$ & $<0.001$ \\
\hline History of rhematic heart disease & 152 & 32 & $21.1 \%(14.6-27.5 \%)$ & $2.2(1.5-3.2)$ & $<0.001$ \\
\hline Chronic kidney disease & 416 & 144 & $34.6 \%(30.0-39.2 \%)$ & $4.8(3.9-5.9)$ & $<0.001$ \\
\hline Malignancy & 90 & 28 & $31.1 \%(21.5-40.7 \%)$ & $3.7(2.3-5.8)$ & $<0.001$ \\
\hline Smoking & 1355 & 208 & $15.4 \%(13.4-17.3 \%)$ & $1.6(1.3-1.9)$ & $<0.001$ \\
\hline Organ transplant recipient & 57 & 3 & $5.3 \%(-0.5-11.1 \%)$ & $0.44(0.14-1.4)$ & 0.43 \\
\hline
\end{tabular}




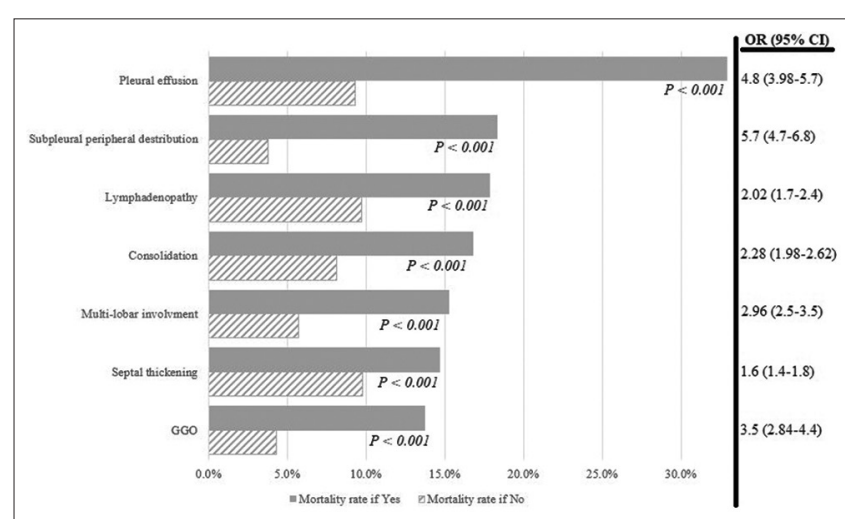

Figure 3: The mortality rate when any of the CT findings is present (Yes) compared to its absence (No)

A retrospective cohort study of 191 hospitalized COVID-19 patients in Wuhan, China from December $29^{\text {th }}, 2019$ till January $31^{\text {st }}, 2020$ reported the death of 54 patients with a mortality rate of $28.3 \%$. However, they didn't report the stratification of mortality as per disease severity. In a meta-analysis of 14 studies including 4659 hospitalized COVID-19 patients, the overall mortality rate was $25.5 \%$ [19]. A higher mortality rate of $32.7 \%$ was reported in high-risk severe patients admitted to ICU in Lombardy, Italy. The in-hospital mortality rates published in these studies are comparable to ours.

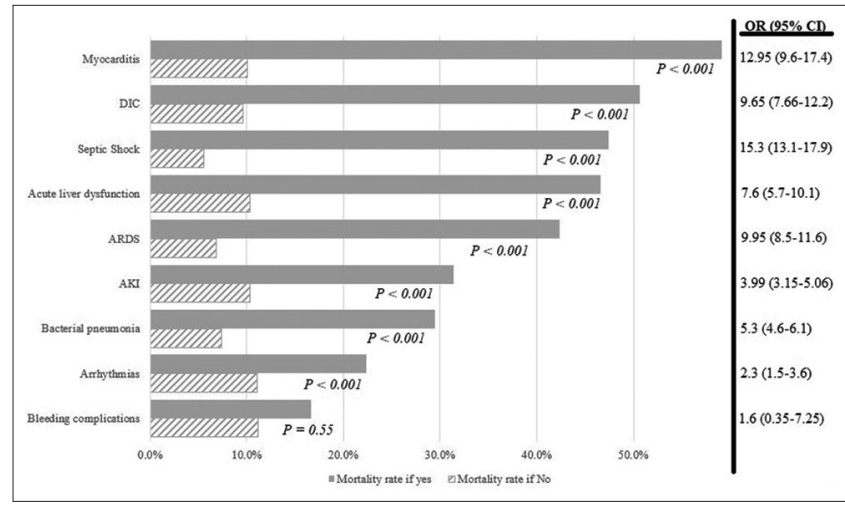

Figure 4: The mortality rate with the different reported complications
In addition to the baseline severity of illness identified on hospital admission and the occurrence of complications during hospital course, the clinical and laboratory features associated with in-hospital mortality were age >60-years-old, male gender, COPD, DM, hypertension, CAD, chronic liver disease, malignancy, CKD, neutrophilia, lymphopenia, high CRP, ALT and AST levels, and higher admission serum creatinine and ferritin levels. The OR reported in our study suggested a strong association of the in-hospital mortality with age >60-years-old, DM, hypertension, chronic liver disease, CKD, malignancy, septic shock, myocarditis, ARDS, DIC, acute liver dysfunction, lymphadenopathy, pleural effusion, and CT finding of multilobar involvement.

Several studies revealed higher mortality rates with advancing age [18], [20], [21]. A study by Berenguer et al. involving 4035 patients in Spain showed a higher mortality rate with increasing age $>60$-years-old (OR: $7.5 ; 95 \% \mathrm{Cl} 6-9.4$ ) compared to (OR: $4.7 ; 95 \%$ Cl 4.1-5.4) reported in our study [22]. This might be secondary to comorbidities linked to advancing age and decreased immune response. CKD, malignancy and liver cirrhosis were reported to be strongly associated with mortality in COVID-19 patients with an OR for CKD ranging from 3.6 in many studies to 9.4 in one metaanalysis study, and OR for malignancy and liver cirrhosis of 2.3 to 2.8 , respectively [19], [22]. In addition to their significant impact on mortality, the higher incidence rates of hypertension $(33.4 \%)$ and DM $(30.9 \%)$ add to their importance as measures of association with mortality in COVID-19 patients. Hypertension and DM were reported as the most common comorbidities that impact mortality in many studies [19], [22]. In our study, hypertension and DM caused 3.9 and 4.6 folds increase in the odds of death in comparison to other studies [17], [18], [19], [22]. The previously known endothelial dysfunction reported with hypertension and DM might explain their impact on the severity of the disease and the high mortality rate [23], [24]. Similar to other studies, our study reported that the presence of more comorbidities increases the mortality rates apart from the type of comorbidities [22].

Table 3: The baseline laboratory findings in survivors and non-survivors

\begin{tabular}{|c|c|c|c|}
\hline \multirow[t]{2}{*}{ Variable } & Non-Survivors & Survivors & \multirow[t]{2}{*}{$p$ value } \\
\hline & Mean \pm SD $(95 \% \mathrm{Cl})$ & Mean \pm SD $(95 \% \mathrm{Cl})$ & \\
\hline Hemoglobin (g/dL) & $11.8 \pm 2.2(11.6-11.9)$ & $12.4 \pm 2.5(12.3-12.5)$ & $<0.001$ \\
\hline $\operatorname{TLC}\left(\times 10^{3} / \mathrm{ccm}\right)$ & $11.6 \pm 6.4(11.0-12.2)$ & $7.1 \pm 4.1(6.9-7.3)$ & $<0.001$ \\
\hline Neutrophils $\left(\times 10^{3} / \mathrm{ccm}\right)$ & $10.1 \pm 6.7(9.2-10.97)$ & $6.2 \pm 7.1(5.8-6.6)$ & $<0.001$ \\
\hline Lymphocytes $\left(\times 10^{3} / \mathrm{ccm}\right)$ & $1.5 \pm 1.48(1.35-1.65)$ & $1.86 \pm 1.3(1.8-1.92)$ & $<0.001$ \\
\hline Platelets $\left(\times 10^{3} / \mathrm{ccm}\right)$ & $244 \pm 117(234-255)$ & $255 \pm 117(251-260)$ & 0.06 \\
\hline $\mathrm{ESR}(\mathrm{mm} / \mathrm{h})$ & $40.8 \pm 27.8(26.7-54.9)$ & $39.4 \pm 31.2(33.7-45.0)$ & 0.7 \\
\hline CRP (mg/L) & $74.8 \pm 81.9(62.1-87.4)$ & $42.1 \pm 51.7(38.6-45.5)$ & $<0.001$ \\
\hline ALT (IU/L) & $55.1 \pm 154.5(39.5-70.7)$ & $36.2 \pm 63.6(33.3-39.1)$ & $<0.001$ \\
\hline AST (IU/L) & $63 \pm 99.0(53.2-72.8)$ & $36.4 \pm 47.8(34.2-38.5)$ & $<0.001$ \\
\hline Total Bilirubin (mg/dL) & $1.3 \pm 1.1(0.6-2.0)$ & $3.2 \pm 8.8(1.2-5.2)$ & 0.5 \\
\hline INR & $2.1 \pm 8.7(0.9-3.2)$ & $1.5 \pm 5.6(1.1-1.8)$ & 0.19 \\
\hline Serum creatinine $(\mathrm{mg} / \mathrm{dL})$ & $2.0 \pm 2.5(1.8-2.3)$ & $1.2 \pm 2.0(1.1-1.3)$ & $<0.001$ \\
\hline Serum albumin (g/dL) & $3.2 \pm 0.6(3.1-3.3)$ & $3.9 \pm 2.4(3.7-4.1)$ & $<0.001$ \\
\hline D-dimer $(\mathrm{micg} / \mathrm{mL})$ & $5.4 \pm 8.8(2.5-8.2)$ & $2.2 \pm 6.5(1.2-3.2)$ & 0.05 \\
\hline Troponin (ng/mL) & $0.2 \pm 0.3(-0.1-0.4)$ & $0.3 \pm 0.3(0.1-0.5)$ & 0.28 \\
\hline \multirow[t]{2}{*}{ Serum Ferritin (ng/mL) } & $919.1 \pm$ & $450.3 \pm$ & 0.001 \\
\hline & 600.5 (688.2-1149.9) & $409.5(382.7-517.9)$ & \\
\hline RBS (mg/dL) & $213.1 \pm 143.5(179.8-246.5)$ & $163.6 \pm 98.4(153.0-174.1)$ & 0.007 \\
\hline CPK (U/L) & $56.8 \pm 40.5(34.8-78.9)$ & $51.2 \pm 40.7(41.8-60.7)$ & 0.65 \\
\hline
\end{tabular}

RBS: Random blood sugar, CPK: Creatine phosphokinas 
Leukocytosis, lymphopenia, high serum CRP, ALT, AST, and ferritin levels reported in our study were associated with higher mortality rates. Similarly, Berenguer et al. reported significantly higher mortality with higher neutrophil count and lower lymphocyte count. They reported also higher CRP, ALT, and AST in non-survivors [22]. The association of higher mortality rates with leukocytosis, neutrophilia, high CRP, and high ferritin levels might be secondary to the dysregulated immune response in COVID-19 patients or superadded secondary infections [25]. The higher mortality rate associated with lymphopenia might represent a dysregulated cellular immune response characterizing COVID-19 [26]. Combining both, the higher NLR was associated with higher mortality. We reported an in-hospital mortality rate of $26 \%$ in patients with NLR $>3.1$ compared to $5.2 \%$ in patients with NLR <3.1. Similar results were reported in earlier studies [27]. The elevated serum creatinine, ALT, AST, and low albumin levels might explain the higher mortality reported in chronic liver disease and CKD. We reported a non-significant tendency for higher D-dimer levels in non-survivors. Contrary to this, a significant tendency for higher D-dimer levels in non-survivors was reported by many other investigators [17], [28] representing the coagulopathy pattern in COVID-19.

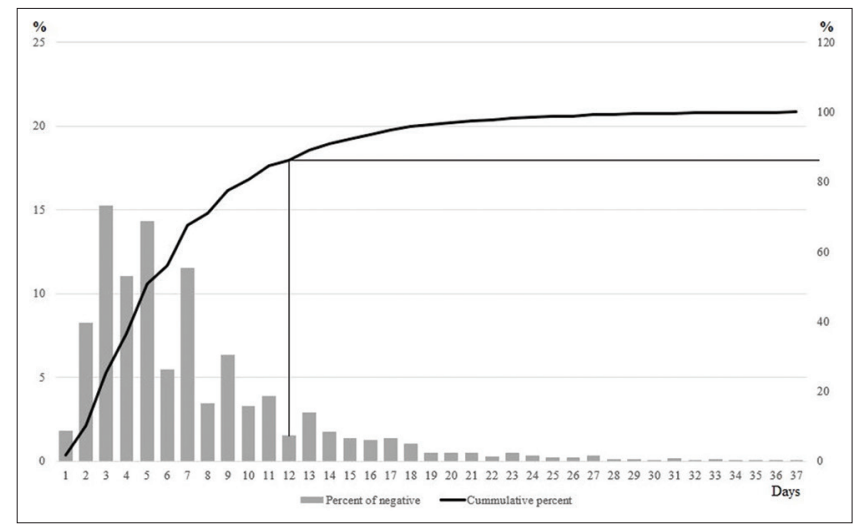

Figure 5: The pattern of turning PCR negative after starting treatment protocol

The most common CT finding was the GGOs which were reported in $73.1 \%$ of patients. Its' presence showed a more than 3 folds increase in the odds of death in our cohort of study participants. Despite their lower incidence of occurrence, the presence of consolidation, pleural effusion, or lymphadenopathy was associated with a significantly higher mortality rate indicating a complicated hospitalization course. The GGOs were reported to be the most common CT findings, and measure of severity and association with mortality in many other studies [17], [18].

Bacterial pneumonia was reported in $>17 \%$ of our study participants. Other studies have reported pneumonia in $10.6-91.1 \%$ of their study participants [18], [22]. The incidence rates of acute kidney injury, septic shock, ARDS, and other complications reported in our study were comparable to other studies [17]. The incidence rates of cardiac arrhythmias and acute liver injury were $1.4 \%$ and $2.5 \%$, respectively, despite using hydroxychloroquine as a standard of care in the Egyptian COVID-19 management protocol. This contradicts the safety concern about the use of hydroxychloroquine in hospitalized COVID-19 patients [29], [30].

Our study showed negative RT-PCR conversion rates of $15.2 \%$ by the $3^{\text {rd }}$ day of treatment and $80.7 \%$ by the $10^{\text {th }}$ day of treatment. Hu et al. revealed similar negative RT-PCR conversion rates of $10.2 \%$ by the $7^{\text {th }}$ day of treatment, $62.7 \%$ by the $14^{\text {th }}$ day of treatment, and $91.2 \%$ by the $21^{\text {st }}$ day of treatment, respectively [31]. They also stated that elderly patients and patients with chest tightness are more likely to have delayed negative RT-PCR conversions [31].

\section{Strengths and limitations}

Our study has strengths. There were on-site visits by the scientific steering committee members to verify compliance with the Egyptian COVID-19 management protocol. The incidence rates of the clinical efficacy outcomes were estimated, information was collected on all relevant potential confounders, recall bias was prevented, and the causal inference was strengthened. On the other hand, the study has limitations. There were inadequate reporting and analysis of our interventions data so, couldn't specify the pivotal medication which played an essential role in the management of the COVID-19 disease. Updates to the Egyptian COVID-19 management protocol were not applied to the current study. The documentation process for laboratory investigations in the quarantine hospitals was inefficient in the early phase of the study with subsequent missing data for the continuous laboratory variables. Despite the study limitations, we collected complete data for the categorical variables.

\section{Conclusions}

This multicenter, retrospective cohort study investigated the demographic, clinical, laboratory, and radiologic features associated with in-hospital mortality in the Egyptian COVID-19 patient population and confirmed the higher in-hospital mortality rate in patients with comorbidities. Double-blinded randomized controlled trials are warranted to make an inference about the treatment effect of the different management elements. 


\section{References}

1. World Health Organization. WHO Director-General's. Opening Remarks at the Media Briefing on COVID-19-11 March 2020. Geneva: World Health Organization; 2020. Available from: https://www.who.int/dg/speeches/detail/who-director-generals-opening-remarks-at-the-media-briefing-on-covid-19---11march-2020 [Last accessed on 2020 Aug 07].

2. Cucinotta D, Vanelli M. WHO declares COVID-19 a pandemic. Acta Biomed. 2020;91(1):157-60. https://doi.org/10.23750/abm. v91i1.9397

\section{PMid:32191675}

3. Gorbalenya AE, Baker SC, Baric RS, de Groot RJ, Drosten C, Gulyaeva $A A$, et al. The species severe acute respiratory syndrome-related coronavirus: Classifying 2019-nCoV and naming it SARS-CoV-2. Nat Microbiol. 2020;5(4):536-44. https:// doi.org/10.1038/s41564-020-0695-z

PMid:32123347

4. Wu Z, McGoogan JM. Characteristics of and Important Lessons from the Coronavirus Disease 2019 (COVID-19) Outbreak in China: Summary of a report of 72314 cases from the Chinese center for disease control and prevention. JAMA 2020;323(13):1239-42. https://doi.org/10.1001/jama.2020.2648 PMid:32091533

5. Wang D, Hu B, Hu C, Zhu F, Liu X, Zhang J, et al. Clinical characteristics of 138 hospitalized patients with 2019 novel Coronavirus-infected pneumonia in Wuhan, China. JAMA. 2020;323(11):1061-9. https://doi.org/10.1001/jama.2020.1585 PMid:32031570

6. World Health Organization. Coronavirus Disease 2019 (COVID-19) Situation Report-26 2020. Geneva: World Health Organization; 2020. Available from: https://www.who.int/docs/ default-source/coronaviruse/situation-reports/20200215sitrep-26-covid-19.pdf?sfvrsn=a4cc6787 2 [Last accessed on 2020 Nov 03].

7. Hassany $M$, Abdel-Razek $W$, Asem $N$, AbdAllah $M$, Zaid H. Estimation of COVID-19 burden in Egypt. Lancet Infect Dis. 2020;20(8):896-7. https://doi.org/10.1016/ S1473-3099(20)30319-4

PMid:32353346

8. World Health Organization. WHO R\&D Blueprint: Informal Consultation on Prioritization of Candidate Therapeutic Agents for use in Novel Coronavirus 2019 Infection, Geneva, Switzerland, 24 January 2020. Geneva: World Health Organization; 2020.

9. Fantini J, Di Scala C, Chahinian H, Yahi N. Structural and molecular modelling studies reveal a new mechanism of action of chloroquine and hydroxychloroquine against SARS-CoV-2 infection. Int J Antimicrob Agents. 2020;55(5):105960. https:// doi.org/10.1016/j.ijantimicag.2020.105960

PMid:32251731

10. Yao X, Ye F, Zhang M, Cui C, Huang B, Niu P, et al. In vitro antiviral activity and projection of optimized dosing design of hydroxychloroquine for the treatment of severe acute respiratory syndrome Coronavirus 2 (SARS-CoV-2). Clin Infect Dis. 2020;71(15):732-9. https://doi.org/10.1093/cid/ciaa237 PMid:32150618

11. FDA. Hydroxychloroquine or Chloroquine for COVID-19: Drug Safety Communication-FDA Cautions Against Use Outside of the Hospital Setting or a Clinical Trial Due to Risk of Heart Rhythm Problems. United States: FDA; 2020. Available from: https://www.fda.gov/safety/medical-product-safety-information/ hydroxychloroquine-or-chloroquine-covid-19-drug-safetycommunication-fda-cautions-against-use [Last accessed on 2020 Aug 07].
12. Gao J, Tian Z, Yang X. Breakthrough: Chloroquine phosphate has shown apparent efficacy in treatment of COVID-19 associated pneumonia in clinical studies. Biosci Trends. 2020;14(1):72-3. https://doi.org/10.5582/BST.2020.01047 PMid:32074550

13. Gautret P, Lagier JC, Parola P, Hoang VT, Meddeb L, Mailhe M, et al. Hydroxychloroquine and azithromycin as a treatment of COVID-19: Results of an open-label non-randomized clinical trial. Int J Antimicrob Agents. 2020;56(1):105949. https://doi. org/10.1016/j.ijantimicag.2020.105949 PMid:32205204

14. Gautret P, Lagier JC, Parola P, Hoang VT, Meddeb L, Sevestre J, et al. Clinical and microbiological effect of a combination of hydroxychloroquine and azithromycin in 80 COVID-19 patients with at least a six-day follow up: A pilot observational study. Travel Med Infect Dis. 2020;34:101663. https://doi.org/10.1016/j. tmaid.2020.101663 PMid:32289548

15. Doane DP, Seward LE. Measuring skewness: A forgotten statistic. J Stat Educ. 2011;19:1-18.

16. Shapiro SS, Wilk MB. An analysis of variance test for normality (complete samples). Biometrika. 1965;52:591-611. https://doi. org/10.1093/biomet/52.3-4.591

17. Zhou F, Yu T, Du R, Fan G, Liu Y, Liu Z, et al. Clinical course and risk factors for mortality of adult inpatients with COVID-19 in Wuhan, China: A retrospective cohort study. Lancet. 2020;395(10229):1054-62. https://doi.org/10.1016/ S0140-6736(20)30566-3

PMid:32171076

18. Guan W, Ni Z, Hu Y, Liang W, Ou C, He J, et al. Clinical characteristics of Coronavirus disease 2019 in China. N Engl J Med. 2020;382(18):1708-20. https://doi.org/10.1056/ NEJMoa2002032

PMid:32109013

19. Tian W, Jiang W, Yao J, Nicholson CJ, Li RH, Sigurslid HH, et al. Predictors of mortality in hospitalized COVID-19 patients: A systematic review and meta-analysis. J Med Virol. 2020;92(10):1875-83. https://doi.org/10.1002/jmv.26050 PMid:32441789

20. Richardson S, Hirsch JS, Narasimhan M, Crawford JM, McGinn T, Davidson KW, et al. Presenting characteristics, comorbidities, and outcomes among 5700 patients hospitalized with COVID-19 in the New York city area. JAMA. 2020;323(20):2052-9. https:// doi.org/10.1001/jama.2020.6775 PMid:32320003

21. Goyal P, Choi JJ, Pinheiro LC, Schenck EJ, Chen R, Jabri A, et al. Clinical Characteristics of COVID-19 in New York City. N Engl J Med. 2020;382(24):2372-4. https://doi.org/10.1056/ nejmc2010419

PMid:32302078

22. Berenguer J, Ryan P, Rodríguez-Baño J, Jarrín I, Carratalà J, Pachón J, et al. Characteristics and predictors of death among 4,035 consecutively hospitalized patients with COVID-19 in Spain. Clin Microbiol Infect. 2020;26(11):1525-136. https://doi. org/10.1016/j.cmi.2020.07.024 PMid:32758659

23. Brandes RP. Endothelial dysfunction and hypertension. Hypertension. 2014;64(5):924-8. https://doi.org/10.1161/ hypertensionaha. 114.03575 PMid:25156167

24. Avogaro A, Albiero M, Menegazzo L, De Kreutzenberg $S$, Fadini GP. Endothelial dysfunction in diabetes: The role of reparatory mechanisms. Diabetes Care. 2011;34 Suppl 2:S285-90. https://doi.org/10.2337/dc11-s239 PMid:21525470 
25. Zeng F, Huang Y, Guo Y, Yin M, Chen X, Xiao L, et al. Association of inflammatory markers with the severity of COVID-19: A meta-analysis. Int J Infect Dis. 2020;96:467-74. https://doi. org/10.1016/j.ijid.2020.05.055

PMid:32425643

26. Li G, Fan Y, Lai Y, Han T, Li Z, Zhou P, et al. Coronavirus infections and immune responses. J Med Virol. 2020;92(4):424-32. https:// doi.org/10.1002/jmv.25685

PMid:31981224

27. Liu Y, Du X, Chen J, Jin Y, Peng L, Wang HH, et al. Neutrophilto-lymphocyte ratio as an independent risk factor for mortality in hospitalized patients with COVID-19. J Infect. 2020;81(1):e6-12. https://doi.org/10.1016/j.jinf.2020.04.002

PMid:32283162

28. Du RH, Liang LR, Yang CQ, Wang W, Cao TZ, Li M, et al. Predictors of mortality for patients with COVID-19 pneumonia caused by SARSCoV-2: A prospective cohort study. Eur Respir J. 2020;55(5):2000524. https://doi. org/10.1183/13993003.00524-2020

PMid:32269088

29. Lofgren SM, Nicol MR, Bangdiwala AS, Pastick KA Skipper CP, Pullen MF, et al. Safety of hydroxychloroquine among outpatient clinical trial participants for COVID-19. Open Forum Infect Dis. 2020;7(11):ofaa500. https://doi. org/10.1101/2020.07.16.20155531

\section{PMid:33204764}

30. Lane JC, Weaver J, Kostka K, Duarte-Salles T, Abrahao MT, Alghoul $\mathrm{H}$, et al. Safety of hydroxychloroquine, alone and in combination with azithromycin, in light of rapid wide-spread use for COVID-19: A multinational, network cohort and selfcontrolled case series study. MedRxiv. 2020;2020:20054551. https://doi.org/10.1101/2020.04.08.20054551

31. Hu X, Xing Y, Jia J, Ni W, Liang J, Zhao D, et al. Factors associated with negative conversion of viral RNA in patients hospitalized with COVID-19. Sci Total Environ. 2020;728:138812. https://doi. org/10.1016/j.scitotenv.2020.138812 